\title{
SEISMIC BEHAVIOUR AND RETROFIT OF PRE-1970's AS- BUILT EXTERIOR BEAM-COLUMN JOINTS REINFORCED BY PLAIN ROUND BARS
}

\author{
A. Liu ${ }^{1}$ and R. Park ${ }^{2}$
}

\begin{abstract}
Four exterior beam-column joints reinforced by plain round bars designed according to pre-1970's codes were subjected to simulated seismic loading. Each of the test units was full size in scale. The main test variables were the manner in which the longitudinal beam bars were hooked in the joint core and the level of the axial load applied to the columns. The amount of transverse reinforcement in the beams, columns and joint cores was very small, as was typical of the pre-1970's.
\end{abstract}

The tests on the units demonstrated that the available stiffness and strength was low when the axial load was zero. The final failure occurred due to opening of the beam bar hooks in tension and column bar buckling, irrespective of the hook details of the beam bars. The presence of axial compressive load of $0.25 \mathrm{f}_{\mathrm{c}}{ }^{\prime} \mathrm{A}_{\mathrm{g}}$ on the columns delayed the failure initiated by the beam bar hooks, leading to much improved stiffness and strength of the units. In one unit with beam bar hooks bent away from the joint core, the column regions adjacent to the joint core were jacketed with fibre-glass and the unit when tested showed much improved stiffness and strength.

When compared with the results of similar units reinforced by deformed bars, the units reinforced by plain round bars showed less joint shear distortion but more opening of beam bar hooks in tension and column bar buckling. As a result, premature concrete tension cracking failure along the outer layer of column bars adjacent to the beam bar hooks was enhanced, and the attained stiffness and the force strength were significantly lower, especially the stiffness.

\section{INTRODUCTION}

There has been increasing emphasis in many countries on seismic assessment and retrofit of existing reinforced concrete structures designed to the pre-1970's codes in recent years $[1,2,7]$.

A research program on Seismic Assessment and Retrofit of Existing Reinforced Concrete Structures has been under way at the University of Canterbury for several years. A number of tests on other as-built and retrofitted reinforced concrete columns and beam-column joint assemblies $[3,4,11,12]$ have been conducted using simulated seismic loading. However, very few tests were conducted on as-built reinforced concrete components reinforced by plain round bars.

Plain bar reinforcement was used in New Zealand until about the mid-1960's when deformed bar reinforcement became widely available. The bond strength of plain bar reinforcement is low, compared with deformed bar reinforcement, particularly during cyclic loading. Conventional theory for flexure and shear was established on the basis of the assumption of perfect bond between the longitudinal reinforcement and the surrounding concrete. Plain round reinforcing bars when used for longitudinal reinforcement hence may lead to very different seismic performance, compared to that with deformed bar reinforcement.
Identified deficiencies associated with exterior beam-column joint components often found in existing reinforced concrete moment-resisting frames, designed before current seismic codes, are inadequate anchorage details of the beam longitudinal reinforcing bars in exterior columns, inadequate quantities of joint shear reinforcement, and inadequate quantities of transverse reinforcement in members, especially in columns $[3,7]$.

This paper reports the results of an experimental study of the effects of the use of plain round bars for reinforcement, the beam bar hook arrangements and the compressive axial load on the columns on the seismic performance of exterior beamcolumn joint assemblies, as well as the improvement in seismic behaviour of exterior beam-column joints achieved by wrapping the column regions above and below the joint core using fibre-glass jacketing. The experimental work involved simulated seismic loading tests on four full-scale asbuilt exterior beam-column joints and one retrofitted as-built exterior beam-column joint.

\section{DETAILS OF AS-BUILT TEST UNITS}

Four full-scale one-way exterior beam-column joint units, which were identical to each other except for the anchorage of the beam longitudinal bars in the exterior columns, were constructed. The beam of each unit was $500 \mathrm{~mm}$ in depth and $300 \mathrm{~mm}$ in width and the column of each unit was $460 \mathrm{~mm}$

\footnotetext{
${ }^{I}$ Ph.D Candidate, University of Canterbury, New Zealand

${ }^{2}$ Emeritus Professor of Civil Engineering, University of Canterbury, New Zealand (Life Member \& Ex-President).
} 
square. Each unit contained plain round longitudinal reinforcement and other reinforcement details typical of the 1950 's construction in New Zealand.

The first two exterior beam-column joint units had the beam bar hooks bent away from the joint core in exterior columns and the straight extension of the bars beyond the bends was four times the bar diameter, as was typical of pre-1970's construction in New Zealand. These two units are referred to as Units EJ1 and EJ3 (see Fig.1). The other two exterior beam-column joint units had the beam bar hooks bent into the joint core in the exterior columns and the straight extension of bars beyond the bends was twelve times the bar diameter as is the current practice [6]. These two units are referred to as Units EJ2 and EJ4 (see Fig.2). The overall dimensions and reinforcing details of as-built Units EJ1 through EJ4 are also shown in Figs. 1 and 2.

The concrete was normal weight. The four units were cast in one stage in the horizontal plane. Tables 1 and 2 list the concrete compressive cylinder strengths of the units at the time of testing, the axial load ratios applied to the columns during testing, and the properties of the reinforcement.

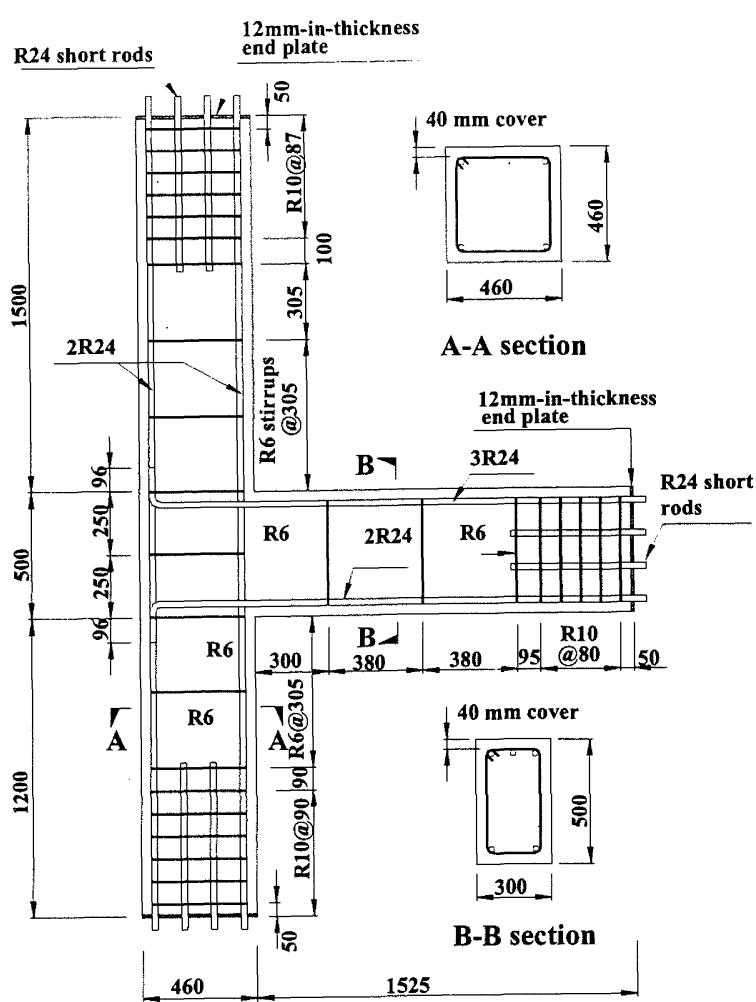

Figure 1: Overall dimensions and reinforcement details of The as-built exterior beam-column joint Units $E J 1$ and $E J 3$.

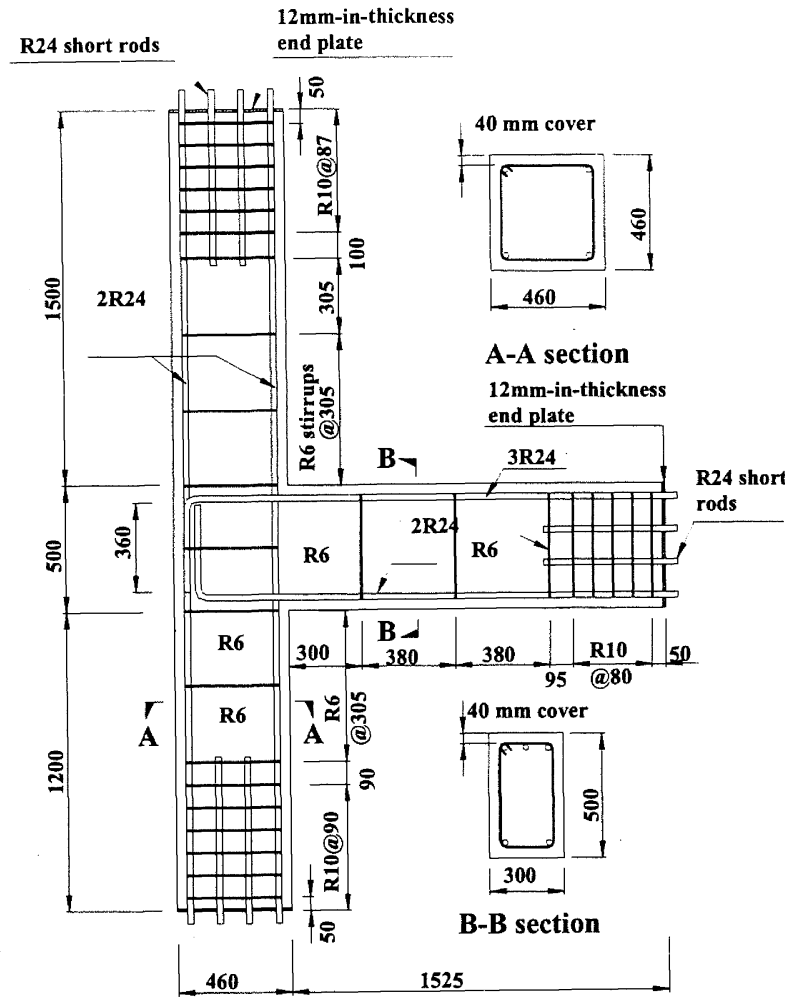

Figure 2: Overall dimensions and reinforcement details of the as-built exterior beam-column joint Units $E J 2$ and EJ4.

Table 1: Reinforcement details of the Units

\begin{tabular}{|l|l|l|l|l|l|l|l|l|l|}
\hline \multirow{2}{*}{$\begin{array}{l}\text { Part of } \\
\text { Unit }\end{array}$} & \multicolumn{4}{|l|}{ Longitudinal Reinforcement } & \multicolumn{2}{l|}{ Transverse Reinforcement } \\
\cline { 2 - 9 } & $\begin{array}{l}\mathrm{d}_{\mathrm{b}} \\
(\mathrm{mm})\end{array}$ & $\begin{array}{l}\mathrm{f}_{\mathrm{y}} \\
\mathrm{MPa}\end{array}$ & $\begin{array}{l}\varepsilon_{\mathrm{y}} \\
\mathrm{x} 10^{-6}\end{array}$ & $\begin{array}{l}\mathrm{p} \\
\%\end{array}$ & $\begin{array}{l}\mathrm{p}^{\prime} \\
\%\end{array}$ & $\begin{array}{l}\mathrm{p}_{\mathrm{t}} \\
\%\end{array}$ & $\begin{array}{l}\mathrm{d}_{\mathrm{b}} \\
(\mathrm{mm})\end{array}$ & $\begin{array}{l}\mathrm{f}_{\mathrm{yt}} \\
\mathrm{MPa}\end{array}$ & $\begin{array}{l}\mathrm{s} \\
(\mathrm{mm})\end{array}$ \\
\hline Beam & 24 & 321 & 1605 & 1.0 & 0.66 & & 6 & 318 & 380 \\
Column & 24 & 321 & 1605 & & & 0.85 & 6 & 318 & 305 \\
\hline
\end{tabular}


Table 2: Concrete compressive strength and axial load levels when testing the Units

\begin{tabular}{|c|c|c|c|c|}
\hline Unit & EJ1 & EJ2 & EJ3 & EJ4 \\
\hline$f_{c}^{\prime}(\mathrm{MPa})$ & 33.7 & 29.2 & 34.0 & 36.5 \\
\hline$N^{*} / A_{g} f_{c}^{\prime}$ & 0 & 0 & 0.25 & 0.23 \\
\hline
\end{tabular}

\section{THEORETICAL CONSIDERATIONS}

\subsection{Seismic Assessment of As-Built Test Units}

\subsubsection{Theoretical Flexural Strengths}

The flexural strengths of the beams and columns of the units were calculated assuming no bond degradation and using the measured material strengths, the code approach recommended by NZS3101: 1995 [6] and a strength reduction factor $\phi$ of unity. They are summarised in Table 3 . The storey horizontal load strengths, which were governed by the beam theoretical flexural strengths for all units, were about the same for all units, being about $67 \mathrm{kN}$ when governed by the beam negative flexural strength, and $45 \mathrm{kN}$ when governed by the beam positive flexural strength.

\subsubsection{Investigation of the Quantities of Transverse Reinforcement}

Transverse reinforcement is required not only for providing shear resistance, but also for preventing bar buckling and confining the compressed concrete, according to NZS3101: 1995. The investigation of the quantities of transverse reinforcement is summarised in Table 4 for the four units. For all units, the column shear force strengths estimated using the measured material strengths and a strength reduction factor $\phi$ of unity were adequate, compared to the column shear demand when the theoretical flexural strength of the units was developed, according to both the method of NZS3101: 1995 and the method of Reference 8. However, the beam shear force strengths, estimated also using the measured material strengths and a strength reduction factor of unity, were quite inadequate, being about $20 \%$ and $50 \%$ of the shear demand when the theoretical flexural strengths of the unit was developed, according to the method of NZS3101: 1995 and the method of Reference 8, respectively. The available joint shear strengths estimated using the procedure proposed in Reference 8 are adequate for all units except for Unit EJ1 which had the beam bar hooks bent away from the joint core. NZS3101: 1995 does not give a method for calculating the available shear capacity of existing beamcolumn joints. The method of Reference 8 was based on test results.

The amount of transverse reinforcement needed for the prevention of the longitudinal bars from buckling and for the confinement of the compressed concrete by NZS3101: 1995 was also computed and is compared with the actual quantities in Table 4. Table 4 illustrates that neither the spacing nor the cross sectional area of the beam and column transverse reinforcement met the requirement of NZS3101: 1995 for preventing longitudinal bar buckling and for confining the compressed concrete. Furthermore, the distance between the first set of ties in the column and that within the joint core was $305 \mathrm{~mm}$, which is much greater than 6 times the diameter of the column bar, namely, $124 \mathrm{~mm}$, required by NZS3101: 1995. This again indicates possible outer column bar buckling in the vicinity of the joint core.

Table 3: Member Flexural Strengths of the Four Units

\begin{tabular}{|l|l|l|l|l|}
\hline Units & $\begin{array}{l}\text { Beam Positive } \\
\text { Moment }(\mathrm{kN}-\mathrm{m})\end{array}$ & $\begin{array}{l}\text { Beam Negative } \\
\text { Moment }(\mathrm{kN}-\mathrm{m})\end{array}$ & $\begin{array}{l}\text { Column Moment } \\
\text { Moment }(\mathrm{kN}-\mathrm{m})\end{array}$ & $\frac{\sum \mathrm{M}_{\text {column }}}{\mathrm{M}_{\text {beam }}}$ \\
\hline EJ1 & 129 & 190 & $120^{*}$ & $2.1(3.1)$ \\
EJ2 & 128 & 189 & $119^{*}$ & $2.1(3.1)$ \\
EJ3 & 128 & 190 & $392^{* *}$ & $4.3(6.4)$ \\
EJ4 & 129 & 190 & $400^{* * *}$ & $4.4(6.5)$ \\
& & & & \\
\hline
\end{tabular}

(1). * With zero axial column load present

(2). ** With axial column load present of $0.25 \mathrm{f}_{c}{ }^{\prime} \mathrm{A}_{\mathrm{g}}$

(3). *** With axial column load present of $0.23 \mathrm{f}_{\mathrm{c}}{ }^{\prime} \mathrm{A}_{\mathrm{g}}$

(4). The ratios of column moments to beam moments, without brackets, are for clockwise loading, and the values in brackets are for anti-clockwise loading. 
Table 4: Shear, Concrete Confinement and Anti-buckling

\begin{tabular}{|c|c|c|c|c|c|c|c|c|c|}
\hline \multirow{7}{*}{$\begin{array}{l}\text { Shear } \\
\text { Requirements }\end{array}$} & \multirow{2}{*}{$\begin{array}{c}\text { Parts of } \\
\text { Units }\end{array}$} & \multicolumn{4}{|c|}{$\begin{array}{l}\text { Maximum Imposed Shear Force } \\
(\mathrm{kN})\end{array}$} & \multicolumn{4}{|c|}{$\begin{array}{l}\text { Available Shear Strength } \\
\qquad(\mathrm{kN})\end{array}$} \\
\hline & & EJ1 & $\mathrm{EJ} 2$ & EJ3 & EJ4 & EJ1 & $\mathrm{EJ} 2$ & EJ3 & EJ4 \\
\hline & \multirow[t]{2}{*}{ beams } & \multirow[t]{2}{*}{113} & \multirow[t]{2}{*}{113} & \multirow[t]{2}{*}{113} & \multirow[t]{2}{*}{113} & 22 & \multirow{2}{*}{$\begin{array}{l}22 \\
(59)\end{array}$} & 22 & 22 \\
\hline & & & & & & (61) & & $(62)$ & (63) \\
\hline & \multirow[t]{2}{*}{ columns } & \multirow[t]{2}{*}{67.5} & \multirow[t]{2}{*}{67.2} & 67.5 & 67.5 & 156 & \multirow{2}{*}{$\begin{array}{l}147 \\
(304) \\
\end{array}$} & 255 & 257 \\
\hline & & & & & & $(325)$ & & $(512)$ & $(528)$ \\
\hline & joint $(\mathrm{H})$ & 368 & 368 & 368 & 368 & (141) & $(361)$ & $(505)$ & $(933)$ \\
\hline \multirow{2}{*}{$\begin{array}{l}\text { Concrete } \\
\text { Confinement }\end{array}$} & \multirow{2}{*}{$\begin{array}{l}\text { Parts of } \\
\text { Units }\end{array}$} & \multicolumn{3}{|c|}{ Required Amount } & & \multicolumn{4}{|c|}{ Actual Amount } \\
\hline & & \multicolumn{2}{|c|}{$\begin{array}{c}\text { Spacing } \\
\text { (mm) }\end{array}$} & \multicolumn{2}{|c|}{$\begin{array}{l}\text { Area per set } \\
\left(\mathrm{mm}^{2}\right)\end{array}$} & \multicolumn{2}{|c|}{$\begin{array}{l}\text { Spacing } \\
(\mathrm{mm})\end{array}$} & \multicolumn{2}{|c|}{$\begin{array}{l}\text { Area per set } \\
\left(\mathrm{mm}^{2}\right)\end{array}$} \\
\hline \multirow{3}{*}{$\begin{array}{l}\text { and } \\
\text { Anti-buckling }\end{array}$} & beams & \multicolumn{2}{|l|}{$\leq 115$} & \multicolumn{2}{|c|}{$\geq 68$} & \multicolumn{2}{|l|}{380} & \multicolumn{2}{|l|}{56.6} \\
\hline & columns & \multicolumn{2}{|l|}{$\leq 115$} & \multicolumn{2}{|c|}{$\geq 46$} & \multicolumn{2}{|l|}{305} & \multicolumn{2}{|l|}{56.6} \\
\hline & Joints & \multicolumn{2}{|l|}{$\leq 200$} & \multicolumn{2}{|c|}{79} & 250 & & \multicolumn{2}{|l|}{56.6} \\
\hline
\end{tabular}

1. H means horizontal joint shear.

2. ${ }^{+}$Zero axial column load ${ }^{++}$With the compressive axial column load of $1800 \mathrm{kN}$

3. The values with brackets are the estimated shear force capacities using the seismic assessment proposed by Park [8], and the values without brackets are the estimated shear force capacities using current method of NZS3101: 1995[6].

4. The imposed horizontal shear force on the joint at the attainment of the theoretical flexural strength of the units would result in a nominal horizontal joint shear stress $v_{\mathrm{jh}}=V_{j h} / A_{j}$ of $0.32 \sqrt{f_{c}^{\prime}}, 0.31 \sqrt{f_{c}^{\prime}}, 0.33 \sqrt{f_{c}^{\prime}}$ and $0.30 \sqrt{f_{c}^{\prime}} \mathrm{MPa}$, for Units EJ1, EJ2, EJ3 and EJ4, respectively, and $0.055 f_{c}{ }^{\prime}, 0.057 f_{c}{ }^{\prime}, 0.057 f_{c}{ }^{\prime}$ and $0.050 f_{c}{ }^{\prime}$ MPa, for Units EJ1, EJ2, EJ3 and EJ4 respectively.

5. The maximum nominal shear stresses in the columns at the attainment of the theoretical flexural strength of the Units were $0.139 \sqrt{f_{c}^{\prime}}, 0.150 \sqrt{f_{c}^{\prime}}, 0.139 \sqrt{f_{c}^{\prime}}$ and $0.134 \sqrt{f_{c}^{\prime}}$ MPa for Units EJ1, EJ2, EJ3 and EJ4, respectively.

6. The maximum nominal shear stresses in the beams at the negative flexural strengths of the beams were $0.060 \sqrt{f_{c}^{\prime}}$, $0.065 \sqrt{f_{c}^{\prime}}, 0.060 \sqrt{f_{c}^{\prime}}$ and $0.058 \sqrt{f_{c}^{\prime}}$ MPa for Units EJ1, EJ2, EJ3 and EJ4 respectively.

\subsubsection{Anchorage of Beam Longitudinal Reinforcement in Exterior Columns}

The anchorage detail of the beam longitudinal bars in exterior column plays an important role in transfer of forces across the joint core for exterior beam-column joint assemblies. NZS3101:1995 requires the deformed beam bar reinforcement to be bent into the joint core in exterior columns in order to engage the diagonal compressive strut and hence to achieve the best force transmission path across the joint core. The arrangement of the beam longitudinal bar hooks in the exterior columns of Units EJ2 and EJ4 satisfied the current code requirement. For Units EJ1 and EJ3, the arrangement of the beam longitudinal bar hooks in exterior columns did not meet the requirements of the current code.

\subsubsection{Discussion}

In summary, the conducted seismic assessment of units EJ1, EJ2, EJ3 and EJ4 identified a number of critical issues, namely the shear strength of the beams, the amount of transverse reinforcement in the members for the prevention of buckling of the longitudinal reinforcement, the beam bar hook details, and generally the effects of using plain round longitudinal bars.

\subsection{Examination of Joint Shear Resisting Mechanisms \\ 3.2.1 Joint Shear Mechanisms of the Exterior Beam- Column Joints EJ2 and EJ4}

In designing exterior beam-column joints according to NZS3101: 1995[6], the deformed beam longitudinal bars are required to be bent into the joint cores in exterior columns and adequate joint shear reinforcement needs to be provided. The postulated joint shear resisting mechanisms in this case by NZS3101: 1995 are a corner to corner joint concrete compression strut mechanism and a joint truss mechanism as shown in Figure 3. 


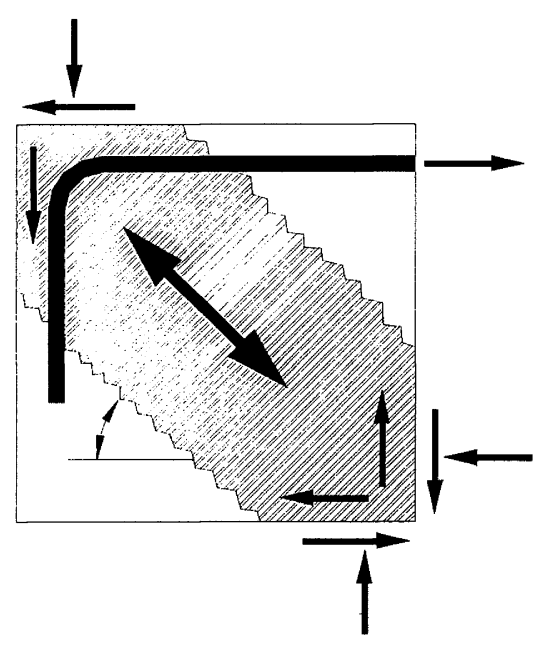

(a) Concrete Strut Mechanism

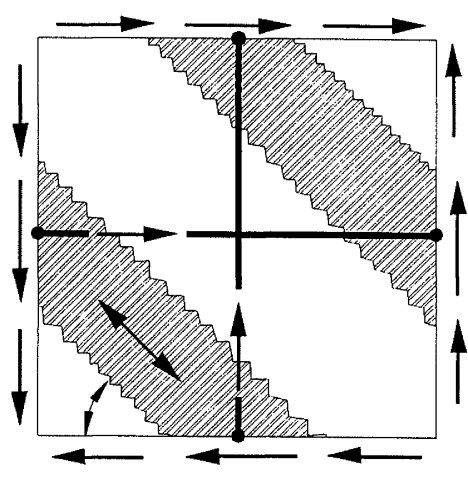

(b) Truss Mechanism

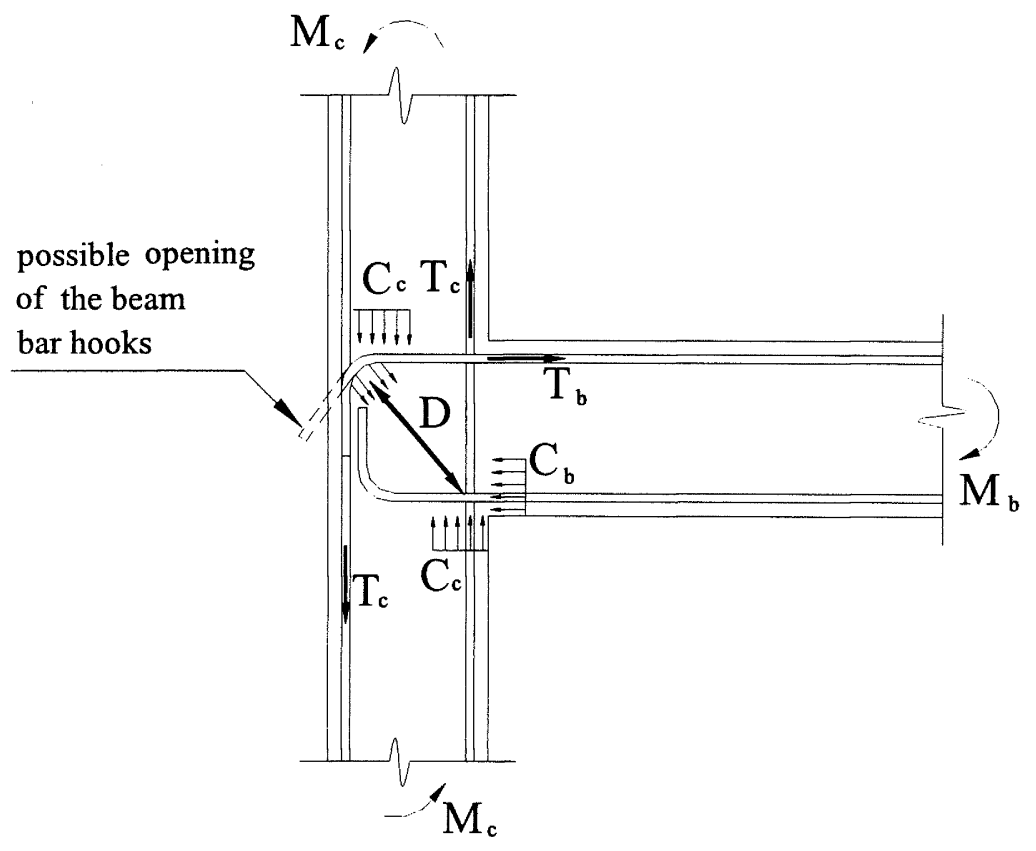

(c) Force Transfer across the Joint Core

Figure 3: Joint shear mechanisms of the exterior beam-column joints with the beam bar hooks bent into the joint core.

Regarding the concrete compression strut mechanism as shown in Fig.3(c), diagonal compression forces are applied to the concrete at the bend of the beam tensile bars, resulting in a tension action around the beam bar hooks. The tension action around the beam bar hooks could be further enhanced due to severe bond degradation and bar slip along the beam tensile bars. Due to the tension action, the beam tensile bars tend to straighten, similar to that of $90^{\circ}$ stirrups, as suggested by the dotted line in Fig.3(c), leading to possible spalling off of the concrete cover and then the loss of protection against the column bar buckling. As a result, premature concrete tension cracking failure along the beam bar hooks could occur. For well-designed exterior beam-column joints, deformed beam bar hooks are bent into the joint core and adequate joint horizontal hoop reinforcement is provided in the region of the beam bar hooks. Part of the beam tension force is transmitted to the joint core concrete by bond and resisted by the postulated joint truss mechanism shown in Fig.3(b). Even if concrete tension cracking occurs along the beam bar hooks, adequate joint horizontal shear reinforcement can restrain the opening action of the beam bar hooks, and an effective concrete strut mechanism can be activated within the joint core. The postulated joint concrete compression strut mechanism in Fig.3(a) of exterior beamcolumn joint assembly can only be fully actuated if the premature failure associated with the opening action of the beam bar hooks can be prevented. 
For Units EJ2 or EJ4, typical design deficiencies were the use of plain bar reinforcement and very limited joint horizontal shear reinforcement present. Hence severe bond degradation would occur along the beam longitudinal bars within the joint core and the beam steel tension force would be mainly transmitted at the bend by the diagonal concrete strut. As a result, the possible premature concrete tension cracking failure initiated by the beam bar hooks would be enhanced, leading to increased demand for the joint horizontal shear reinforcement to prevent such a failure, compared to the case with deformed reinforcing bars. However the joint core of Units EJ2 or EJ4 contained only limited joint shear reinforcement and therefore premature concrete tension cracking failure initiated by the beam bar hooks could lead to the final failure of the system. As a consequence, the effectiveness of the joint concrete strut mechanism could diminish.

\subsubsection{Alternative Joint Shear Mechanism for Units EJ1 or EJ3}

For Units EJ1 or EJ3, neither the arrangement of the beam bar hooks in the exterior columns nor the plain round bars used satisfied the requirements of NZS3101: 1995.

When the beam longitudinal bars are bent out of the joint core in exterior columns as for Units EJ1 or EJ3, the beam steel tensile force transfer within the bend has to be as illustrated in Figure 4 . The resistance within the bend to the beam steel tension force could potentially cause the concrete tension cracking in the columns initiated by the beam bar hooks, and such concrete tension cracking could be further enhanced by column bar buckling above and below the joint core. If this does occur, the beam bar hooks will open up as suggested in Fig.4.

Due to the use of plain bar reinforcement for Units EJ1 and EJ3, severe bond degradation and bar slip would be expected along the longitudinal reinforcement. As a result, the beam steel tension forces at the column inner face would be mainly transmitted within the bend of the beam bars. Hence the possibility of the above described premature failure associated with the interaction of the opening action of the beam bar hooks and column bar buckling would increase.

However, an alternative force path with the beam bar hooks bent out of the joint cores in exterior columns could be developed should extensive column transverse reinforcement be provided adjacent to but outside of the joint core [10]. Extensive column transverse reinforcement within the region of the beam bar hooks can not only control the premature concrete tension cracking failure initiated by the beam bar hooks, but also generate at the outer column face clamping forces which are necessary for the formation of the inclined concrete compression strut actions of $\mathrm{D}$ across the joint core and $D_{1}$ in the columns. In this case, the available column flexural strength would reduce. However, the seismic performance of the whole system would be irrespective of the amount of joint core shear reinforcement in this case, contrary to Units EJ2 or EJ4.

For the exterior beam-column joint Units EJ1 or EJ3, column transverse reinforcement was sparse and the first set of column transverse reinforcement was far away from the beam faces. Hence the alternative joint force path was unlikely to form for Units EJ1 and EJ3.

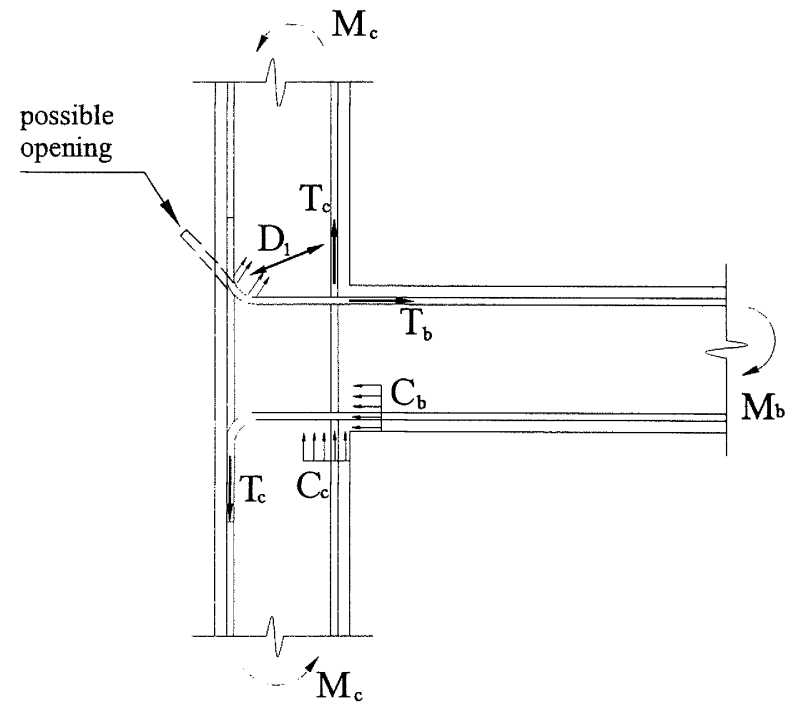

(a) Opening of beam bar hooks

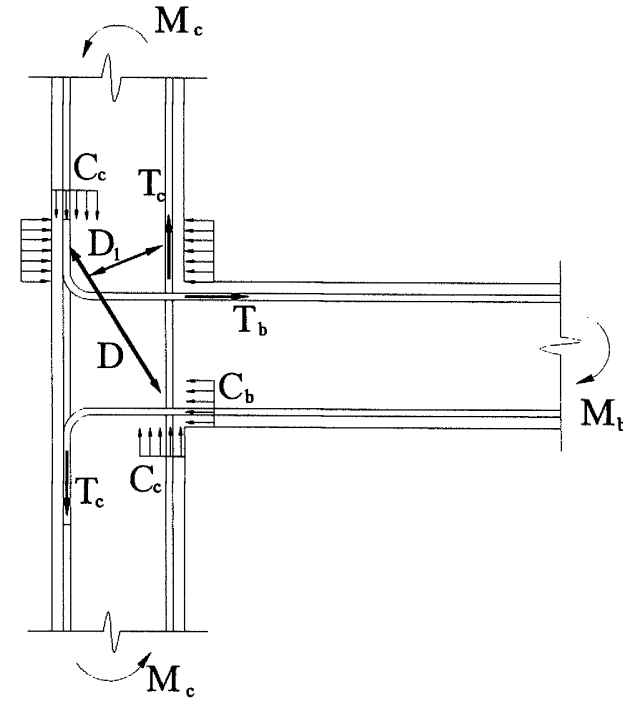

(b) Possible Alternative Joint Force

Path in Exterior Beam-Column

Joints with the Beam Bar Hooks

Bent Away from the Joint Core

Figure 4: Possible alternative joint force path in exterior beam-column joints with the beam bar hooks bent away from the joint core. 


\subsubsection{RETROFIT SCHEME USED FOR UNIT REJ1}

The postulation for achieving the alternative joint force path shown in Fig. 4 was testified by conducting simulated seismic loading test on the retrofitted Unit REJ1 (see Figure 5), which was the damaged Unit EJ1.

A fibre-glass jacket of eight layers was used to wrap the column areas of $200 \mathrm{~mm}$ immediately above and below the joint core of the damaged Unit EJ1. The unit then became Unit REJ1. The material properties of fibre-glass are shown in Table 5. Resin injection was used before the fibre-glass iacketing to enhance the damaged bond strength and to repair the cracked regions.

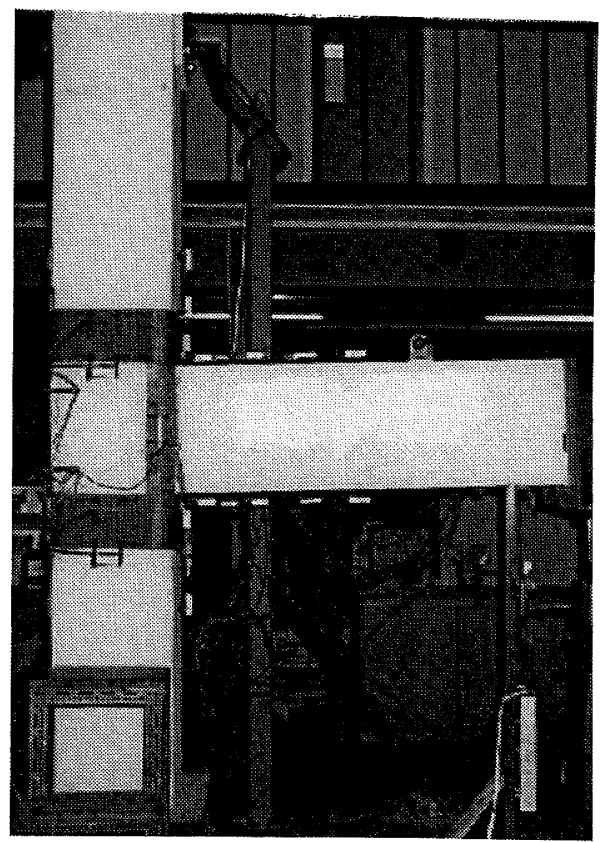

Figure 5: Retrofit scheme using fibre-glass jacketing.

Table 5: Properties of Fibre Glass Wrapping

\begin{tabular}{|l|l|}
\hline Ultimate Tensile Strength & $400 \mathrm{MPa}$ \\
\hline Design Tensile Strength & $100 \mathrm{MPa}$ \\
\hline Elastic Modulus & $20000 \mathrm{MPa}$ \\
\hline Cross Sectional Area Per Wrap & $508\left(\mathrm{~mm}^{2}\right)$ \\
\hline
\end{tabular}

\section{TESTING OF THE UNITS}

The units were tested under simulated seismic loading with or without axial column load. Seismic loading was simulated by vertically displacing the beam ends while the column ends were held against horizontal translation. For Units EJ3 and EJ4, the constant compressive axial load of $1800 \mathrm{kN}$ was applied to the column by a steel loading rig, which consisted of the top and bottom steel reaction beams, hydraulic rams and two high strength tension rods, producing a column axial load ratio of 0.25 for Unit EJ3 and 0.23 for Unit EJ4. To accommodate the column end rotations and maintain a vertical axial column load during testing, a rocker seat was used for tests on Units EJ3 and EJ4 between the bottom of the column and the top surface of the bottom steel reaction beam of the axial loading rig. The loading method is illustrated in Figures 6 and 7. The first two loading cycles at the beam ends were load-controlled, involving one cycle to $50 \%$ of the theoretical flexural strength of the unit and one cycle to $75 \%$ of the theoretical flexural strength of the unit. These two cycles in the elastic range were followed by a series of deflection-controlled inelastic cycles comprising two full cycles at displacement ductility factors of $1,2,3$ etc. The "first yield" displacement was found by extrapolating the measured stiffness at $75 \%$ of the theoretical flexural strength of the unit linearly up to the theoretical strength of the unit [9].

The deformations of members and beam-column joints were monitored using linear potentiometers. Of particular importance was that for all tests the beam fixed-end rotations (due to bond degradation in the joint core) were measured using pairs of linear potentiometers located next to the column inner face. Electrical resistance strain gauges were placed on the column transverse reinforcement at different locations, typically, above and below the joint core as well as within the joint core, and the longitudinal reinforcement strains were also monitored by electrical resistance strain gauges.

\section{TEST RESULTS OF THE EXTERIOR BEAM- COLUMN JOINTS}

\subsection{General}

Figures 6 and 7 show the method of loading the test units.

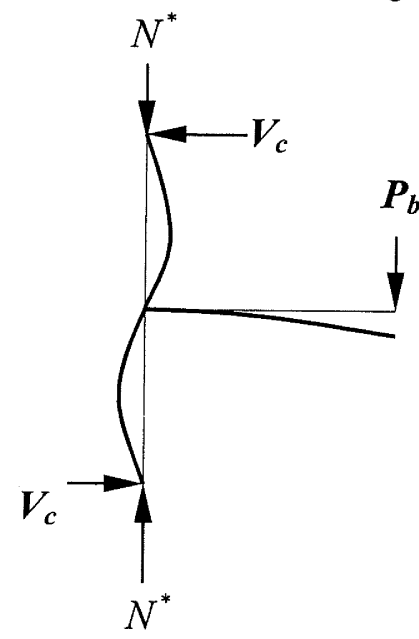

Figure 6: Method of loading Units EJ3 and EJ4.

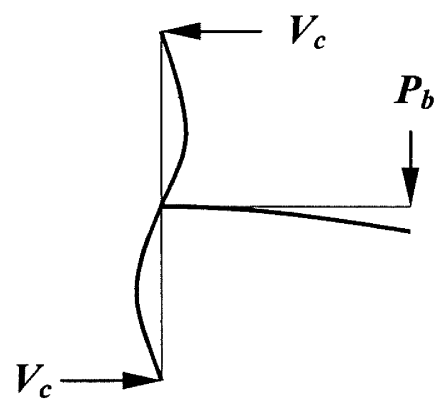

Figure 7: Method of loading Units EJI and EJ2. 
Figure 8 shows Units EJ1 through EJ4 at the end of the testing. It is evident in Fig. 8 that the performance of the beams and columns was dominated by degrading member flexural behaviour although the theoretical assessment

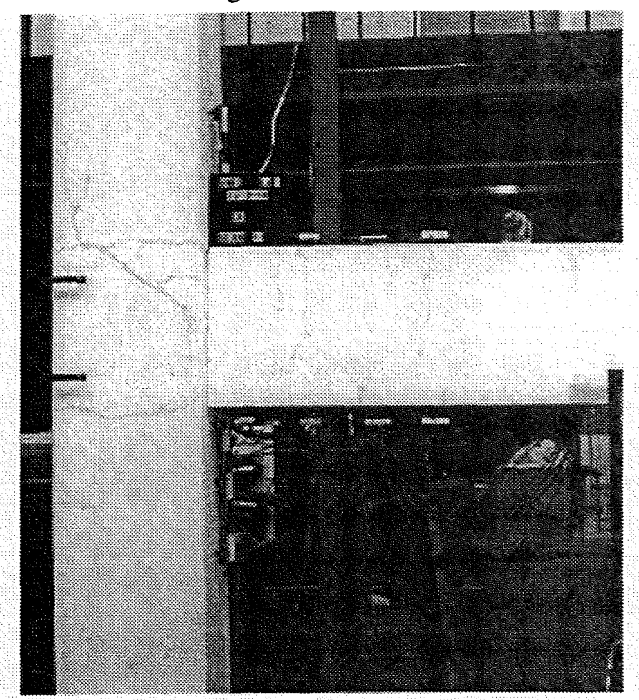

(a) Unit EJ1

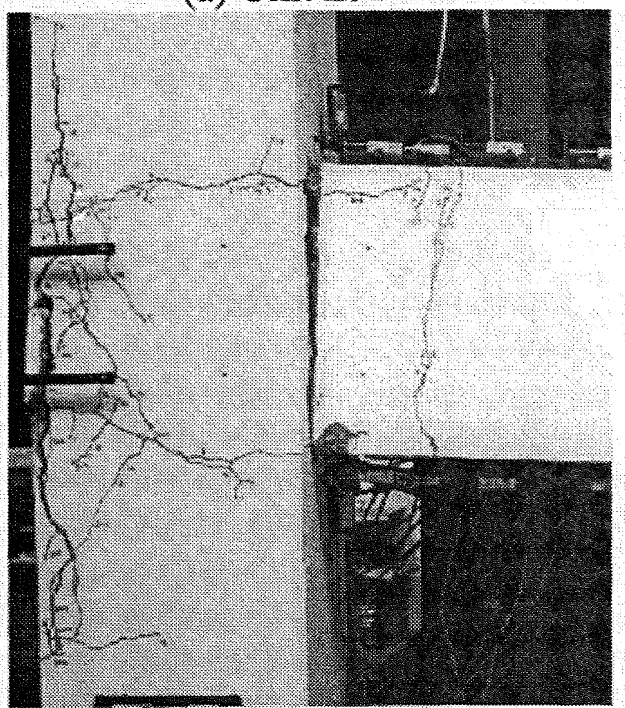

(c) Unit EI2 predicted inadequate beam shear resistance, and degrading member flexural behaviour was due to the premature bond failure along the member longitudinal reinforcement. The joint cores of all units were of good integrity until the end of

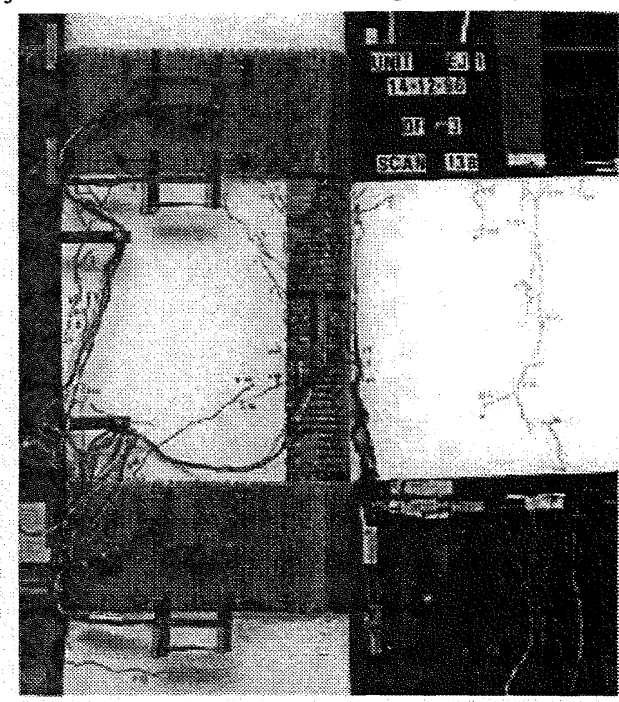

(b) Unit REJ1

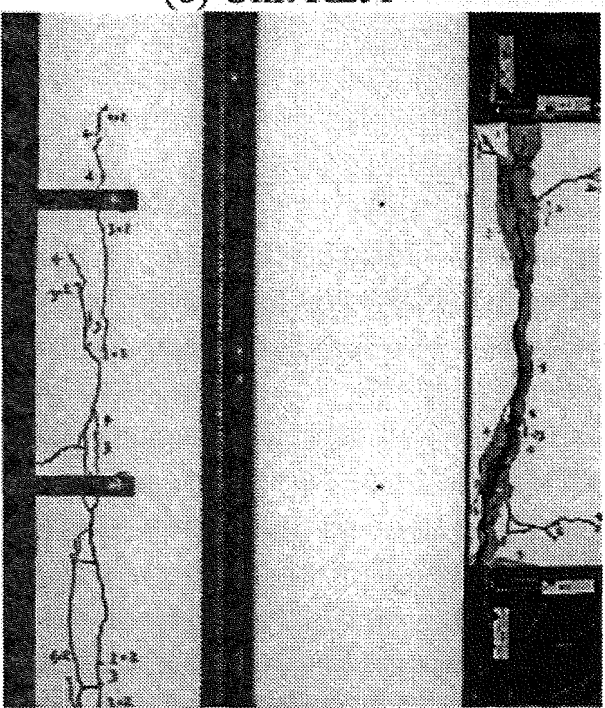

(d) Unit EJ3

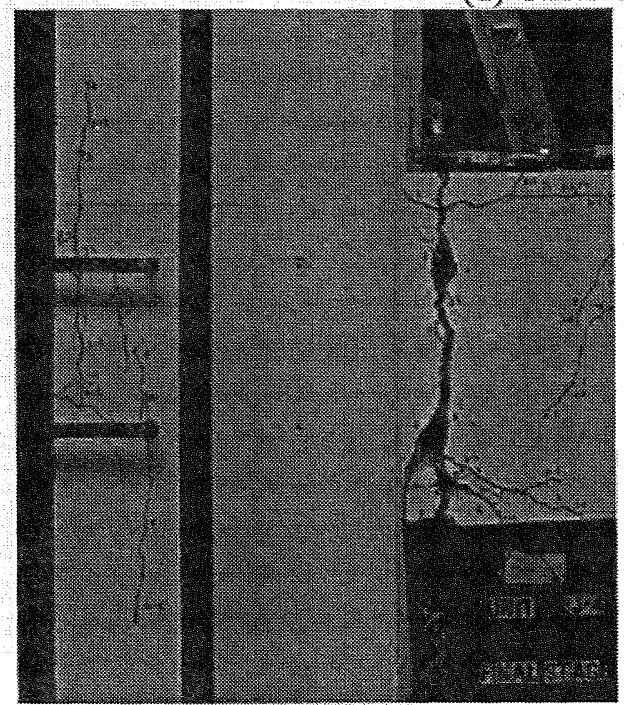

(e) Unít E]4

Figure 8: Final appearance of exterior beam-column joints tested. 
testing. The seismic performance of Units EJ1 and EJ2, which were otherwise identical but had alternative arrangements of the beam bar hooks and were tested with zero axial column load present, was controlled by concrete tension cracking along the beam bar hooks, irrespective of the arrangements of the beam bar hooks. Such concrete tension cracking was due to opening of the beam bar hooks in tension, which was further accelerated by column bar buckling adjacent to the joint core.

In comparison, the seismic performance of Units EJ3 and EJ4, which were respectively identical to Unit EJ1 and EJ2 but were tested under simulated seismic loading with a constant compressive column axial load, was controlled by concrete tension cracking along the outer layer of column longitudinal reinforcement adjacent to and within the joint core, which was again due to the combined action of the straightening of the beam bar hooks in tension and column bar buckling. However, the compressive column axial load for Units EJ3 and EJ4 delayed such premature concrete tension cracking, leading to much improved seismic performance, compared with the tests on Units EJ1 and EJ2.

\subsection{Load-versus-Displacement and Drift Hysteresis Loops for As-Built Units}

Figure 9 shows storey shear versus storey horizontal displacement and drift hysteresis loops for as-built Units EJ1 through EJ4. Also shown in Fig.9 is the theoretical storey shear strength, $\mathrm{V}_{\mathrm{i}}$, which was calculated using the NZS3101: 1995 [8] code approach based on the beam theoretical flexural strength.

\subsection{Stiffness Performance}

The first yield displacement could not be obtained for Unit EJ1 using the method described in Section 4 as the load did not reach $0.75 \mathrm{~V}_{\mathrm{i}}$. The displacement measured at the loading cycle of $0.5 \mathrm{~V}_{\mathrm{i}}$ for Unit EJ1 was equivalent to a storey drift of $0.62 \%$. The equivalent stiffness at this stage was $1.7 \mathrm{kN} / \mathrm{mm}$, which was only $33 \%$ of the estimated initial stiffness of 5.1 $\mathrm{kN} / \mathrm{mm}$ based on an often-assumed effective moments of inertia of $50 \%$ of the gross values for the beams and columns. Significant stiffness degradation observed in the second elastic loading cycle suggested that the measured initial stiffness for Unit EJl would have been lower than 1.7 $\mathrm{kN} / \mathrm{mm}$ should the loading peak of $0.75 \mathrm{~V}_{\mathrm{i}}$ have been attained. The measured displacements at first yield for Units EJ2, EJ3 and EJ4, found using the method described in Section 4, were equal to a storey drift of $1.5 \%, 0.59 \%$ and $0.53 \%$ respectively. Equivalently, the measured initial stiffnesses using the method described in Section 4 were $1.2 \mathrm{kN} / \mathrm{mm}, 3.0$ $\mathrm{kN} / \mathrm{mm}$ and $3.3 \mathrm{kN} / \mathrm{mm}$ on average, being about $24 \%, 60 \%$ and $65 \%$ of the estimated stiffness for Units EJ2, EJ3 and EJ4, based on an effective moment of inertia of $50 \%$ of the gross values, respectively. Evidently the tested units reinforced by plain bars were very flexible when the axial column load was low, and the existence of compressive axial column load of about $0.25 \mathrm{f}_{\mathrm{c}} \mathrm{A}_{\mathrm{g}}$ caused the initial structural stiffness to increase by about $180 \%$.

The effect of the type of steel on the structural stiffness performance can be investigated by comparing the observed stiffness behaviour of Unit EJ2 with that observed for Hakuto's Unit O6 [3]. Hakuto's Unit O6 was identical to Unit EJ2 but with deformed bar reinforcement, and was also tested with zero axial column load. The measured initial stiffness at first yield for Hakuto's Unit O6 was $47 \%$ of its estimated value, which was also based on the effective moment inertia of $50 \%$ of the gross moment of inertia for the beams and columns. This indicates that the flexibility of the tested system with plain bar reinforcement was twice that with deformed bar reinforcement. The increase in flexibility as a result of using plain reinforcing bars is considerable.

\subsection{Strength Performance}

Unlike well-designed exterior beam-column joints, where the theoretical flexural strength or even the over-strength can be achieved [5], the maximum storey shear strengths attained by Units EJ1 and EJ2 with zero axial column load, which occurred at a storey drift of $1.5 \%$, were $57 \%$ and $75 \%$ of the theoretical flexural strengths of the units respectively. In comparison, the storey shear strengths attained by Units EJ3 and EJ4 with constant column axial load of about $0.25 \mathrm{f}_{\mathrm{c}}{ }^{\prime} \mathrm{A}_{\mathrm{g}}$, which occurred at a storey drift of about $1.2 \%$ during clockwise loadings and at a storey drift of $0.6 \%$ during anticlockwise loadings, were higher, being $87 \%$ and $91 \%$ of the theoretical flexural strengths of the units respectively.

It is evident that the arrangement of the beam bar hooks in exterior columns made a significant difference to the available strength when the units were tested under simulated seismic loading with zero axial column load. Bending the beam bar hooks into the joint core in exterior columns, as for Unit EJ2, resulted in higher flexural strength than bending the beam bar hooks out of the joint core as for Unit EJ1. This is readily explained. Column transverse reinforcement above and below the joint core of Unit EJ1 has two functions: one is to prevent the column longitudinal reinforcement from buckling and the other is to provide an alternative joint shear resisting force path. In comparison, the column transverse reinforcement above and below the joint core of Unit EJ2 only needs to prevent the column longitudinal reinforcement from buckling.

Also apparent in Fig.9 is that the existence of a constant axial column load of about $0.25 \mathrm{f}_{\mathrm{c}}{ }^{\prime} \mathrm{A}_{\mathrm{g}}$ enhanced the attained storey shear strengths of Units EJ3 and EJ4, which were about 1.2 to 1.5 times the attained storey shear strengths of Units EJ1 and EJ2. The compressive axial column load of about $0.25 \mathrm{f}_{\mathrm{c}} \mathrm{A}_{\mathrm{g}}$ for tests on Units EJ3 and EJ4 enhanced the force transfer from the beam tension steel to the joint core concrete by bond within the joint region, and hence greatly reduced the amount of the beam steel force needed to be transferred at the bend by the joint concrete strut. As a consequence, the available force strength associated with the premature concrete tension failure initiated by the beam bar hooks in tension was greatly enhanced. In this case, the effect of the arrangement details of the beam bar hooks diminished. The reality of the still slightly low available strengths observed for Units EJ3 and EJ4 were mainly because of the bond deterioration along the beam longitudinal reinforcement, which prevented the theoretical beam flexural strengths from being developed.

Compared to Hakuto's tests on Units $\mathrm{O} 7$ and $\mathrm{O} 6$ where the attained storey shear strengths were respectively $75 \%$ and $100 \%$ of the theoretical strength of the units, the tests on Units EJ1 and EJ2 showed a reduction of up to $25 \%$ in the available strength due to the use of plain bar reinforcement. This was once again mainly attributed to the enhanced premature concrete cracking failure initiated by the beam bar hooks which occurred for Units EJ1 and EJ2 as a result of using plain longitudinal reinforcement. Severe bond degradation and slip along the beam longitudinal reinforcement due to the use of plain bar reinforcement also caused the member flexural strengths to reduce. 


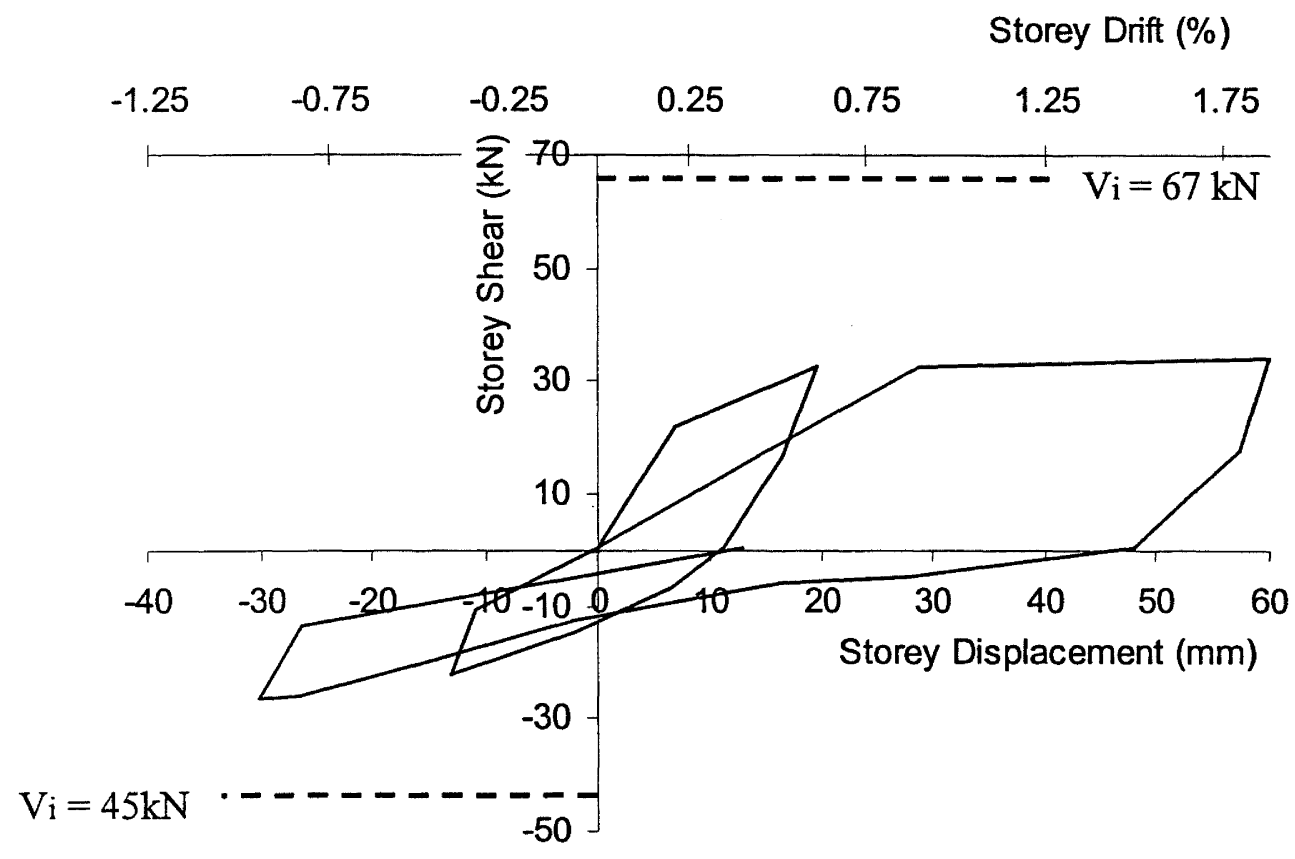

(a) Unit EJ1

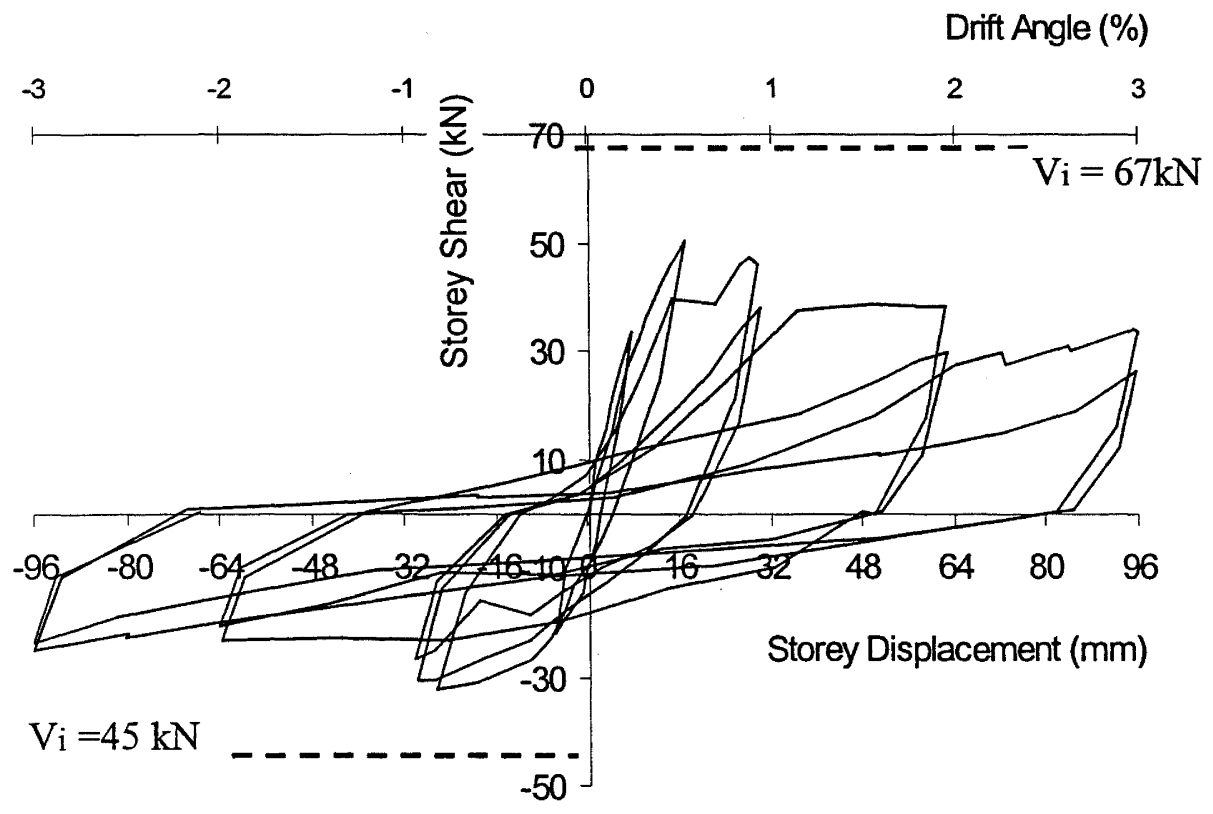

(b) Unit REJ1

Figure 9: Storey shear versus storey displacement and drift hysteresis loops. 


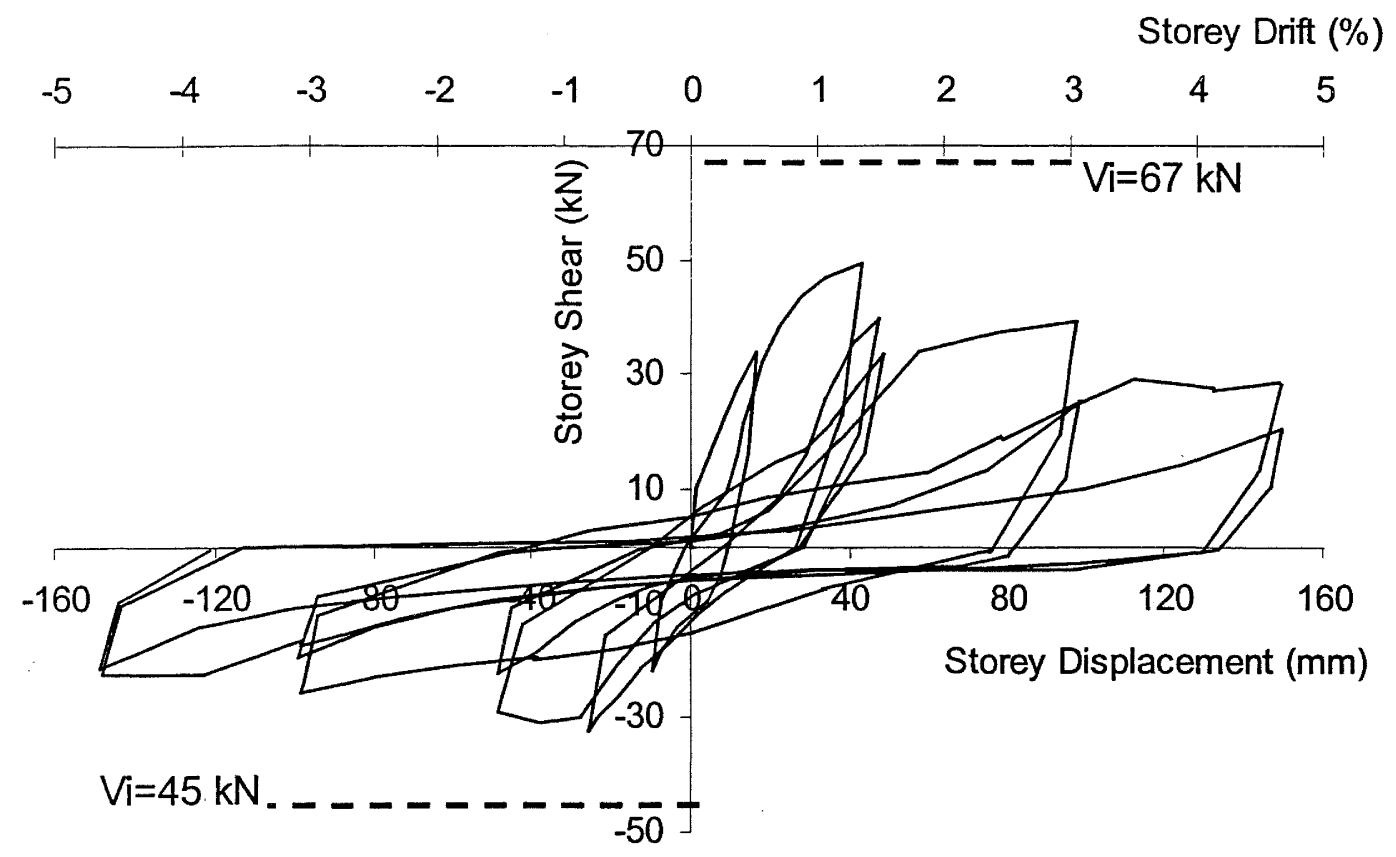

(c) Unit EJ2

Drift Angle (\%)

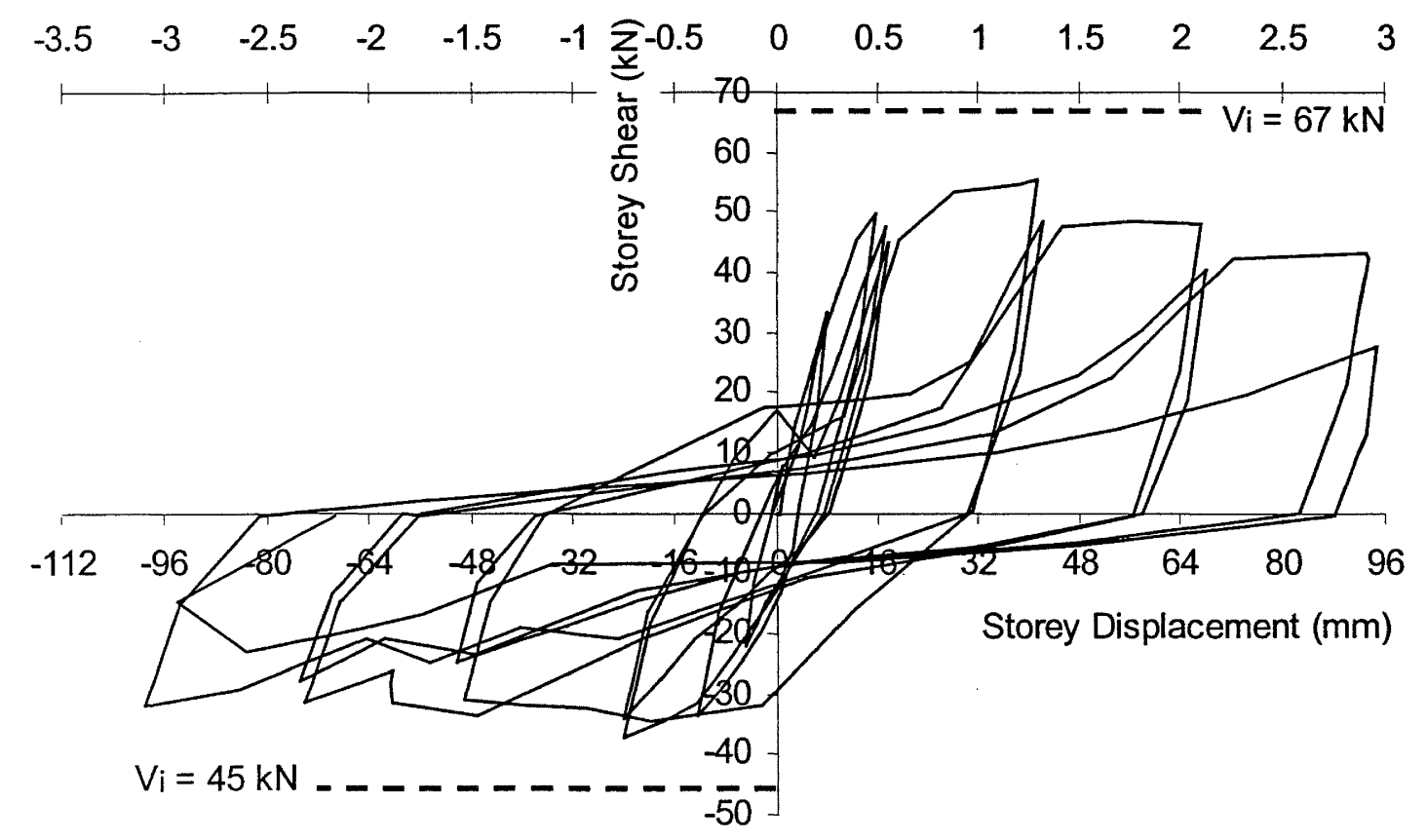

(d) Unit EJ3

Figure 9 continued: Storey shear versus storey displacement and drift hysteresis loops. 


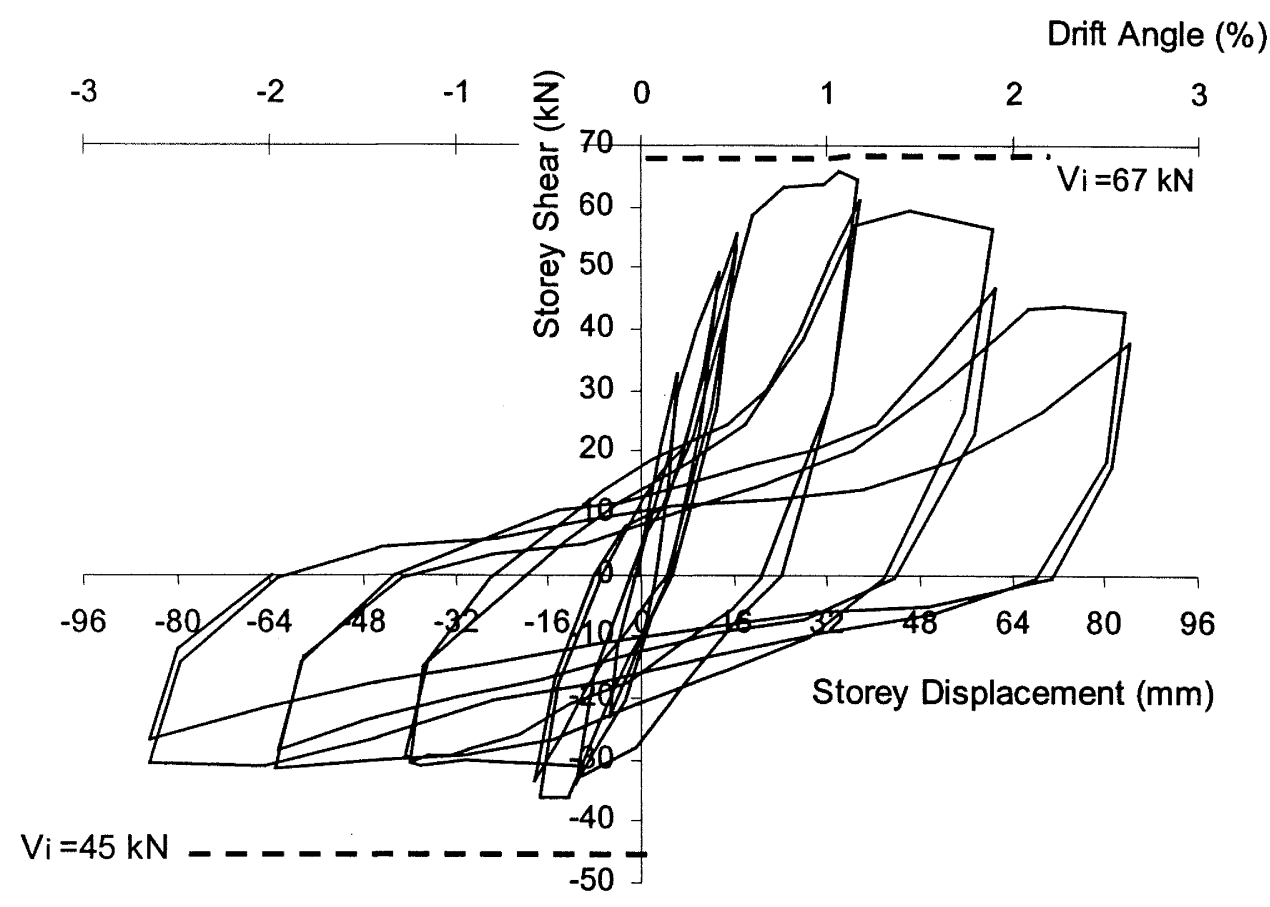

(e) Unit EJ4

Figure 9 continued: Storey shear versus storey displacement and drift hysteresis loops.

\subsection{Joint Behaviour}

The measured maximum nominal horizontal joint shear stress for as-built Units EJ1, EJ2, EJ3 and EJ4 was small, being $0.17 \sqrt{ } \mathrm{f}_{\mathrm{c}}{ }^{\prime}, 0.23 \sqrt{ } \mathrm{f}_{\mathrm{c}}{ }^{\prime}, 0.27 \sqrt{ } \mathrm{f}_{\mathrm{c}}{ }^{\prime}$ and $0.30 \sqrt{ } \mathrm{f}_{\mathrm{c}}{ }^{\prime} \mathrm{MPa}$, respectively. The induced maximum joint shear distortion was also small, being only about $0.55 \%$ when the units were tested with zero axial column load, and it was much smaller, being about $0.0065 \%$ when the units were tested with compressive axial column load of about $0.25 \mathrm{f}_{\mathrm{c}}{ }^{\prime} \mathrm{A}_{\mathrm{g}}$ present, irrespective of the beam bar hook details.

Of particular interest is that the measured strain in the column transverse reinforcement at the beam flexural tensile face was much higher than the strains in the column transverse reinforcement measured within the column spans and at the centre of the joint core of Units EJ1 and EJ3. The transverse reinforcement in the columns being highly stressed at the beam face for Units EJ1 and EJ3 was apparently not due to high column shear demand, but was a consequence of the need for developing the alternative joint force path, as suggested in Section 3. By comparison, the measured column transverse reinforcement strain at beam face for Units EJ2 and EJ4 was well below the measured column transverse reinforcement strains at the centre of the joint cores. This occurred because the joint shear reinforcement at the centre of the joint core of Units EJ2 or EJ4 was needed not only for resisting joint shear force, but also for restraining the opening action of the beam bar hooks, as suggested in Section 3. This evidence testified that different beam bar hook details accentuate the need for column transverse reinforcement at different locations, as described in Section 3.

\subsection{Observed Beam and Column Behaviour}

The measured steel strains along the longitudinal reinforcement of the beams and columns were generally larger than the values estimated by conventional flexural theory at the beam-column interfaces, indicating that conventional flexural theory overestimates the member moments. This was because severe bond degradation along the longitudinal reinforcement greatly violated the assumption of plane sections. The observed beam and column performance was dominated by degrading flexural behaviour for all units, and the steel strains measured on the transverse reinforcement were well below the steel yield strain. This suggests that the code approach and the procedure in the current seismic assessment method for shear strength greatly underestimate the available member shear resistance when plain bars are used. The measured member flexural deformations mainly concentrated in the member fixed-end regions, similar to that observed for tests on interior beam-column joint units with plain bar reinforcement [6].

\section{$5.7 \quad$ Summary}

In summary, the units when tested with zero axial column load demonstrated very low stiffness and strength. The arrangements of the beam bar hooks had significant effects on the seismic behaviour of the units. However, the units when tested with constant compressive axial column load of about $0.25 f_{c}{ }^{\prime} A_{g}$ present, showed significant improvement in the attainment and maintenance of the available strength and stiffness. The compressive axial column load of about $0.25 f_{c}{ }^{\prime} A_{g}$ caused the effect of the beam bar hook details on the system seismic behaviour to be less apparent. 


\section{IMPROVEMENT IN THE SEISMIC BEHAVIOUR OF AS-BUILT DAMAGED EXTERIOR BEAM- COLUMN UNIT BY FIBRE-GLASS JACKETING}

The storey shear force versus storey displacement and storey drift hysteresis loops measured for the retrofitted unit REJ1 is also shown in Fig. 9. Comparison of Fig. 9 (a) and Fig. 9(b) shows that wrapping the column regions above and below the joint core using fibre-glass jacketing actuated the postulated alternative joint shear force path, leading to substantial improvement in the structural stiffness and strength of the unit.

The stiffness measured at clockwise $0.5 \mathrm{~V}_{\mathrm{i}}$ for Unit REJ1 was $4.26 \mathrm{kN} / \mathrm{mm}$, and this was 2.37 times the measured initial stiffness of $1.7 \mathrm{kN} / \mathrm{mm}$ for the as-built Unit EJ1 at clockwise loading $0.5 \mathrm{~V}_{\mathrm{i}}$. The lateral confinement provided by the fibreglass jacketing controlled the development of concrete tension cracking initiated by the beam bar end hooks in tension, resulting in much enhanced stiffness performance. The average initial stiffness measured for Unit REJ1 at loading cycle of $0.75 \mathrm{~V}_{\mathrm{i}}$ was $2.1 \mathrm{kN} / \mathrm{mm}$, and this was about $40 \%$ of the estimated initial stiffness, based on 0.5 of the gross section moment of inertia. Obviously the available stiffness of the retrofitted exterior beam-column joint Unit REJ1 was still very low as is to be expected when passive jacketing is used.

The maximum storey shear strengths, which were attained by Unit REJ1 in the loading cycle at $0.75 \mathrm{~V}_{\mathrm{i}}$ for both clockwise and anti-clockwise loading directions, were about $75 \%$ of the corresponding theoretical storey shear strengths of the unit. Compared to the test of Unit EJ1 where the achieved strength was about $55 \%$ of the theoretical flexural strength of the unit, the strength enhancement observed for Unit REJ1 due to wrapping the columns using fibre-glass jackets was up to $20 \%$.

Comparison of the results of tests on Units REJ1 and EJ2 showed that the strength and stiffness performance of retrofitted exterior beam-column joint Unit REJ1 were similar to that of Unit EJ2 with the beam bar hooks bent into the joint core, indicating that external wrapping of the column regions adjacent to the joint core of exterior beamcolumn joints with the beam bar hooks bent away from the joint core can upgrade as-built reinforced concrete frame structures to a similar performance to that with the beam bar hooks bent into the joint cores.

\section{CONCLUSIONS}

The general conclusions reached concerning the joint shearresisting mechanisms of exterior beam-column joints with alternative beam bar hook details in exterior columns were as follows:

1. The development of the postulated joint shear-resisting mechanisms in current seismic codes for exterior beamcolumn joints with the beam bar hooks bent into the joint cores necessitates prevention of the premature failure associated with the opening of the beam bar hooks. Control of such opening action needs sufficient column transverse reinforcement to be provided within the joint core.

2. Use of plain round bar reinforcement makes more likely premature concrete tension cracking failure caused by opening of the beam bar hooks in tension and column bar buckling.

3. To resist joint shear, column transverse reinforcement is needed immediately above and below the joint core, as well as in the joint core, when the beam bar hooks are bent out of the joint core, and column transverse reinforcement is needed within the joint core (in the form of joint horizontal shear reinforcement) when the beam bar hooks are bent into the joint core. The availability of extensive column transverse reinforcement adjacent to the joint cores when the beam bar hooks are bent out of the joint cores can engage the development of the postulated alternative joint force path.

The experimental study led to the following conclusions:

1. Four full-scale one-way exterior beam-column joint units, which were identical except for the arrangements of the beam bar hooks in the joint cores, were tested under simulated seismic loading with either zero axial column load or with a compressive axial column load of about $0.25 \mathrm{f}_{\mathrm{c}}{ }^{\prime} \mathrm{A}_{\mathrm{g}}$. The units contained plain round longitudinal reinforcement, had a small amount of transverse reinforcement in the beams, columns and joint cores, and were representative of a reinforced concrete frame building constructed in New Zealand in 1950 's. Unit EJ1, with the beam bar hooks bent away from the joint core, was retrofitted by wrapping the column regions above and below the joint core using fibre-glass jackets after being tested.

2. The units when tested with zero axial column load, Units EJ1 and EJ2, were controlled by premature concrete tension cracking initiated by the beam bar hooks in tension, irrespective of the beam bar hook details. Premature concrete tension cracking initiated by the beam bar hooks in tension was due to opening of the beam bar hooks, which was further accelerated by column bar buckling adjacent to the joint core. Different beam bar hook details in exterior columns were found to have significant influences on the performance when the axial column load was low. The attained storey shear force strength by Unit EJ1, with the beam bar hooks bent out of the joint core, was $55 \%$ of the theoretical strength of the unit. In contrast, the attained storey shear strength by Unit EJ2, with the beam bar hooks bent into the joint core, was about $75 \%$ of the theoretical strength of the unit, which occurred at storey drift of about $1.5 \%$. The initial stiffness obtained using the method described in Section 4.1 for Unit EJ 2 was only $24 \%$ of the estimated stiffness, and the initial stiffness could not be obtained using the method described in Section 4.1 for test on Unit EJ1 due to the low strength attainment. Evidently, the tested structure when reinforced by plain round bars would be of very low stiffness and very low strength attainment.

When contrasted with the results from Hakuto's tests on Unit O6 [3], which was otherwise identical to Unit EJ2 but used deformed bar reinforcement, the use of plain longitudinal reinforcement was found to enhance premature concrete tension cracking failure along the beam bar hooks. The resulting flexibility of the unit EJ2 was doubled, and the force strength reduced by about $25 \%$, compared to that of Unit O6.

3. The units when tested with a compressive axial column load of about $0.25 \mathrm{f}_{\mathrm{c}} \mathrm{A}_{\mathrm{g}}$, Units EJ3 and EJ4, showed a large increase in the stiffness and strength. Compressive axial column load delayed premature concrete tension cracking initiated by the beam bar hooks. The effect of different beam bar hook details on the seismic performance of these exterior 
beam-column joint units was very small in this case and the final failure trigger became the large beam fixed-end rotation for Units EJ3 and EJ4.

The attained storey shear strengths by Units EJ3 and EJ4, which occurred at a storey drift of about $1.2 \%$ during clockwise loading and $0.6 \%$ during anti-clockwise loading, were about $85 \%$ to $95 \%$ of the theoretical strength of the units, based on flexural strength, being about 1.2 to 1.5 times the attained strengths by Units EJ1 and EJ2. The attained stiffness by Units EJ3 and EJ4 was about 1.8 times the values for Units EJ1 and EJ2.

4. The plane section assumption is significantly violated when plain round longitudinal bars are used, due to the occurrence of severe bond degradation. As a result, conventional flexural theory overestimates the member flexural strength while conventional shear theory underestimates the member shear force strength.

5. The test on the retrofitted unit with zero axial column load showed that wrapping the column regions using fibreglass jacketing adjacent to the joint core ensured the development of the postulated joint shear force path, leading to much improved stiffness and strength. The increase in the attained storey shear strength was up to $20 \%$. The final failure trigger became the large beam fixed-end rotation in this case.

6. The flexible performance of the units in the elastic range suggests that P- $\Delta$ effects of similar existing reinforced concrete frame buildings should be allowed for. In addition, the interaction of such frames with masonry infills should be considered in conducting structural analysis.

\section{ACKNOWLEDGMENTS}

The financial support of the Earthquake Commission of New Zealand (Project 95/222) is gratefully acknowledged. Thanks are also due to the University of Canterbury for support, particularly to technicians N. Hickey and G. Hill for assistance with the construction and testing of the beamcolumn units. In addition, the contribution of the fibre-glass jacketing by Mr. Rob Irwin of Construction Technique Ltd, Auckland, is also gratefully acknowledged.

\section{NOTATIONS}

$\mathrm{f}_{\mathrm{c}}{ }^{\prime}=$ concrete compressive cylinder strength $(\mathrm{MPa})$

$\mathrm{f}_{\mathrm{y}}=$ yield strength of longitudinal reinforcement (MPa)

$\mathrm{f}_{\mathrm{yt}}=$ yield strength of transverse reinforcement $(\mathrm{MPa})$

$\mathrm{A}_{\mathrm{g}}=$ gross area of column section $\left(\mathrm{mm}^{2}\right)$

$\mathrm{b}=$ width of beam $(\mathrm{mm})$

$\mathrm{d}=$ distance from extreme compression fiber of beam to centroid of beam tension reinforcement $(\mathrm{mm})$

$\mathrm{p}=$ ratio of area of the top beam longitudinal bars to bd of beam

$p^{\prime} \quad=$ ratio of area of the bottom beam longitudinal bars to bd of beam

$\mathrm{p}_{\mathrm{t}}=$ ratio of area of the total column longitudinal bars to column gross area

$\varepsilon_{\mathrm{y}}=$ steel yield strain

$\mathrm{d}_{\mathrm{b}}=$ diameter of longitudinal steel $(\mathrm{mm})$

$s=$ spacing of transverse reinforcement

$\phi=$ the strength reduction factor, being unity here

$\phi_{\mathrm{u}}=$ ultimate curvature $\left(\mathrm{mm}^{-1}\right)$ $\phi_{\mathrm{y}}=$ yield curvature $\left(\mathrm{mm}^{-1}\right)$

$v_{\mathrm{jh}}=$ the nominal horizontal joint shear stress $(\mathrm{MPa})$

$l_{c}=$ storey height, $3200 \mathrm{~mm}$

$l_{b}=$ beam span, $1905 \mathrm{~mm}$

$\mathrm{V}_{\mathrm{i}}=$ theoretical storey shear strength of the unit based on the flexural strength of the beam

$\mathrm{D}=$ joint concrete strut

$D_{1}=$ concrete strut mechanism actuated in columns

\section{REFERENCES}

1. Aoyama, H., "A method for the Evaluation of the seismic Capacity of Existing Reinforced Concrete Buildings in Japan", Bulletin of the New Zealand National Society for Earthquake Engineering, Vol.14, No.3, Sept. 1981, pp105-130

2. ATC, "A Handbook for Seismic Evaluation of Existing Buildings ATC-22", Applied Technology Council, Redwood City, California, ATC21, 1989, 169pp

3. Hakuto, S., Park, R. and Tanaka, H., "Retrofitting of Reinforced Concrete Moment Resisting Frames", Research Report 95-4, Department of Civil Engineering, University of Canterbury, August 1995

4. Liu, A. and Park, R., "Seismic Load Tests on Two Interior Beam-Column Joints Reinforced by Plain Round Bars Designed to Pre-1970s Seismic Codes", Bulletin of the New Zealand National Society for Earthquake Engineering, Vo.31, No.3, Sept. 1998

5. Paulay, T. and Scarpas, A., "The Behaviour of Exterior Beam-Column Joints", Bulletin of the New Zealand National Society for Earthquake Engineering, Vol.14, No.3, Sept. 1981, pp131-144

6. NZS3101: 1995, "The Design of Concrete Structures, NZS3101: 1995", Standards New Zealand, Wellington, 1995

7. Park, R., "Seismic Assessment and Retrofit of Concrete Structures-United States and New Zealand Developments", Proceedings of Technical Conference of New Zealand Concrete Society, Wairakei, 1992, pp18-25

8. Park, R., "A Static Force-Based Procedure for the Seismic Assessment of Existing Reinforced Concrete Moment Resisting Frames", Bulletin of the New Zealand National Society for Earthquake Engineering, Vol.30, No.3, 1997. pp213-226

9. Park, R. "Evaluation of Ductility of Structures and Structural Subassemblages from Laboratory Testing", Bulletin of the New Zealand National Society for Earthquake Engineering, Vol. 22 No.3, 1989, pp155-166

10. Priestley, M.J.N., Seible, F., and Calvi, G. M., "Seismic Design and Retrofit of Bridges", John Wiley \& Sons, Inc., New York, 1996, p686

11. Rodriguez, M. and Park, R., "Seismic Load Tests of Reinforced Concrete Columns Strengthened by Jacketing", Structural Journal of the American Concrete Institute, Vol. 91, No.2, 1994, pp150-159

12. Wallace, J., "Behaviour of Beam Lap Splices under Seismic Loading", Master of Engineering Thesis, Department of Civil Engineering, University of Canterbury, 1996 